\title{
Solitary Digital Nodule in an Infant
}

\author{
Archana Singal $^{a} \quad$ Ishmeet Kaur $^{a}$ Vinod Kumar Arora ${ }^{b}$ \\ Departments of a Dermatology and STD and ${ }^{b}$ Pathology, University College of Medical Sciences and GTB Hospital, \\ University of Delhi, Delhi, India
}

\section{Question}

A 5-month-old female infant was brought to the Dermatology Department with a single, asymptomatic, firm pinkish nodule present over the distal digit of the left second toe. It began as the size of a lentil at birth and progressively increased to attain the present size (Fig. 1). The lesion covered almost the entire second toenail. Parents denied a history of preceding trauma. The baby was playful, her medical and family history being unremarkable. The increasing size of the lesion was of great concern to the parents.

What is your diagnosis?

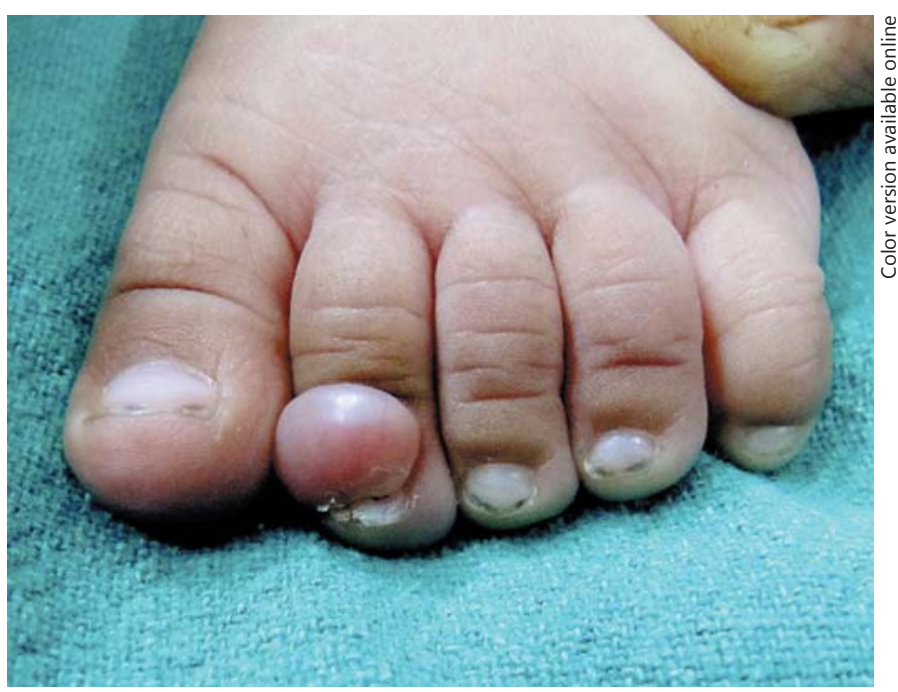

Fig. 1. Erythematous, globular swelling overlying the dorsum of the distal digit of the second left toe.

\section{KARGER}

(C) 2017 S. Karger AG, Basel

E-Mail karger@karger.com

www.karger.com/sad
Prof. Archana Singal

University College of Medical Sciences and GTB Hospital

University of Delhi

Delhi 110095 (India)

E-Mail archanasingal@ hotmail.com 


\section{Answer}

\section{Infantile Digital Fibromatosis}

On request of the parents, an excision biopsy was performed and submitted for histopathology. Hematoxylin and eosin-stained sections (Fig. 2) revealed an unremarkable epidermis and the presence of interlacing fascicles of spindle cells with thick collagen bundles extending from the papillary dermis through the deep dermis into the subcutis. Intracytoplasmic round eosinophilic bodies were identifiable (Fig. 3). Skin appendages were seen entrapped by the fascicles of tumor cells. The clinical and histological features were consistent with the diagnosis of infantile digital fibromatosis (IDF).

IDF, also known as Reye's tumor is a rare benign tumor of fibromatous origin with an unclear etiology. It generally presents in the first year of life as an asymptomatic smooth pinkish nodule overlying the distal phalanx of fingers and toes [1]. The lesion initially shows an indolent or a rapid progression following which it becomes stable and then resolves spontaneously [2]. Histopathology reveals a benign proliferation of myofibroblasts with a characteristic perinuclear eosinophilic inclusion body. The tumor cells stain positive for various immune-histochemical markers including desmin, vimentin, calponin, and alpha-smooth muscle actin [3]. Treatment of IDF remains controversial and includes watchful expectancy for spontaneous resolution, intralesional injections of corti-

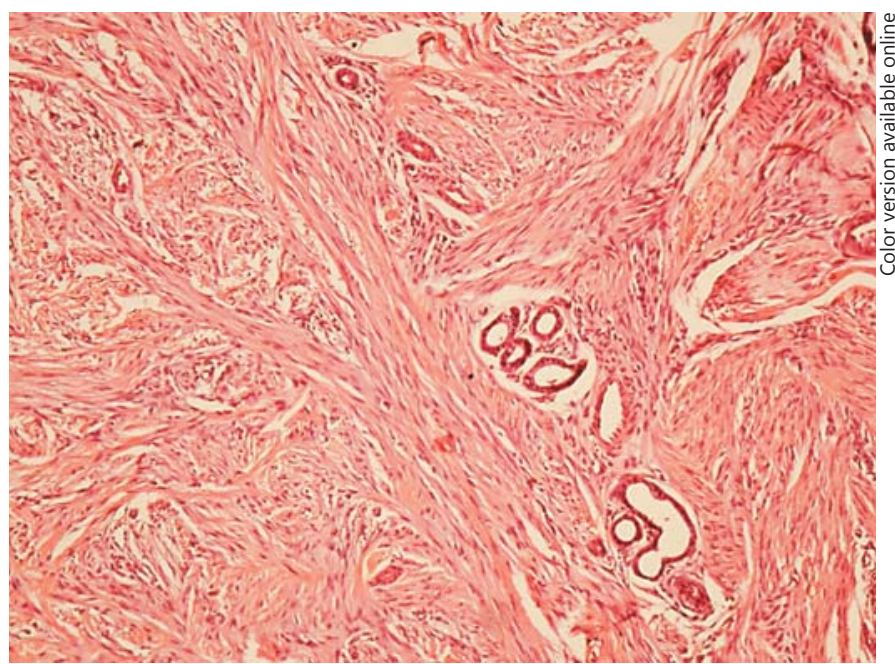

Fig. 2. Interlacing fascicles of spindle-shaped cells in the dermis (HE, $\times 100)$.

Solitary Digital Nodule costeroid and 5-flourouracil, and surgical excision [4]. The latter is undertaken for cosmetic concerns, if there is associated severe dysfunction, and in order to establish the diagnosis. Our decision to excise the lesion was based on the request from the parents, who were deeply concerned about the rapid increase in the size of the lesion. However, due to a high recurrence potential, tendency to resolve spontaneously, and lack of propensity to metastasize, IDF is generally managed with a conservative approach. Our patient did not show any evidence of recurrence on the 8-month follow-up.

\section{Statement of Ethics}

Written consent has been obtained from the patient's parent.

\section{Disclosure Statement}

The authors hereby declare to have no conflict of interest regarding the paper.

\section{Keywords}

Infant · Digital · Fibroma · Spindle cells · Eosinophilic inclusions

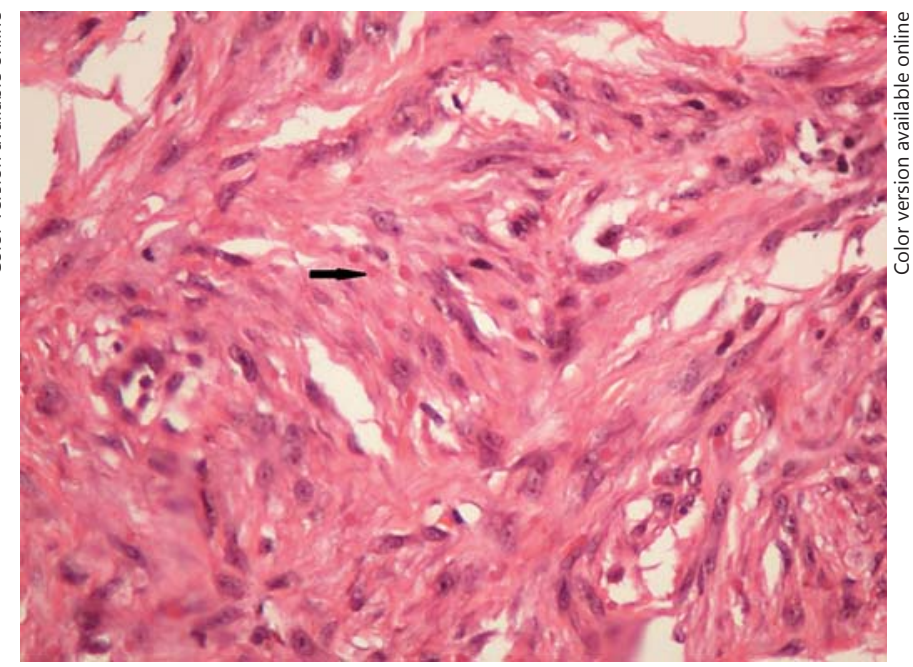

Fig. 3. Round, eosinophilic intracytoplasmic inclusion bodies (black arrow) (HE, ×400). 


\section{References}

1 Marks E, Ewart M: Infantile digital fibroma: a rare fibromatosis. Arch Pathol Lab Med 2016; 140:1153-1156.

2 Failla V, Wauters O, Nikkels-Tassoudji N, Carlier A, André J, Nikkels AF: Congenital infantile digital fibromatosis: a case report and review of the literature. Rare Tumors 2009; 1:e47.
3 Coffin CM, Alaggio R: Fibroblastic and myofibroblastic tumors in children and adolescents. Pediatr Dev Pathol 2012;15(suppl 1):127-180

4 Liu B, Xu ZC, Bao PQ, Hu TZ, Li Y: A case of infantile digital fibromatosis: differential diagnosis and treatment. Int J Dermatol 2014; 53:e16-e18 